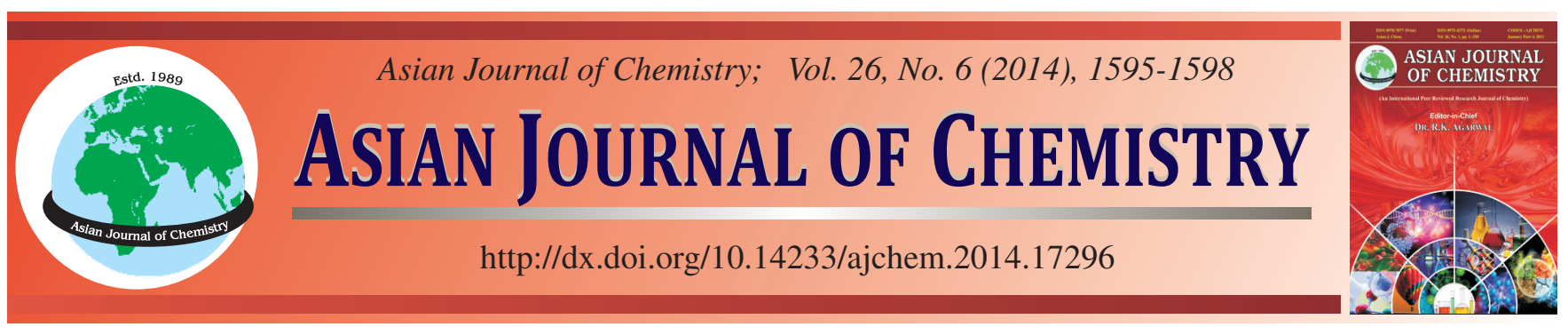

\title{
Viscosity and Antiwashout Properties of Cement Mortar at Low Temperature Seawater Environment $\uparrow$
}

\author{
Heon Chang Kim ${ }^{1}$, In-Kyu JAng ${ }^{2}$ and Seung-Kyu ParK ${ }^{1, *}$
}

${ }^{1}$ Department of Chemical Engineering, Hoseo University, Asan 336-795, Republic of Korea

${ }^{2}$ GENOSS Ltd., Suwon 443-270, Republic of Korea

*Corresponding author: Fax: +82 41 5405758; Tel: +82 41 5409686; E-mail: skpark@ hoseo.edu

\begin{abstract}
Cement mortar is a construction material and generally a mixture of water, cement, sand and sometimes fine gravel. When cement mortar is applied to the seawater construction at low temperature below $0{ }^{\circ} \mathrm{C}$, the flow performance, workability, placement, antiwashout and consolidation should be considered in combination. In this research, the antiwashout and rheological properties of the cement mortar have been investigated with admixtures prepared by adding anionic surfactants, cationic surfactants and polymeric thickeners. Cement mortar formulated by pseudo-polymeric systems, electrostatic association of anionic and cationic surfactants and polymer additive such as poly methyl vinyl ether, showed thixotropic, suitable antiwashout, proper workability and self-leveling properties. Addition of isopropyl alcohol to mixed surfactant admixture decreases the freezing temperature of cement grout to $-7^{\circ} \mathrm{C}$ and increases the workability at cold seawater, but slightly decreases the compressive strength of the cement grout at seawater system.
\end{abstract}

Keywords: Cement mortar, Antiwashout, Thixotropic, Mixed surfactant, Cold seawater.

\section{INTRODUCTION}

In recent years, numerous studies have been done on the interfacial properties of mixtures of various surfactants. For the description of the properties of surfactant blends, the mutual interactions of surfactants as well as their interactions with adjacent phases have been considered. For mixed micelle formation, a simple physical interaction as non-ideal mixtures is possible ${ }^{1}$. When anionic and cationic surfactants are dissolved in water, the surfactants can be present in three different environments: as monomers, incorporated in mixed micelles and as precipitate $^{1,2}$. It is generally known that anionic and cationic surfactants cannot be mixed since they are precipitated on mixing ${ }^{2,3}$. However, many recent studies have shown that mixture of anionic and cationic surfactants can be present stable state and show synergetic properties ${ }^{4-6}$. The mixture of dodecyl benzene sulfonate and quaternary ammonium chloride shows stable state as mixed micelle and provides an excellent suspension, rheological and anti-washout properties after application to cement grouting system ${ }^{6-8}$.

Cement mortar and concrete are the construction material and generally a mixture of water, cement, sand and sometimes fine gravel ${ }^{9}$. In the cement mortar suspension, water and cement mixture, various surfactants systems can be applied to keep mixing the components of them and prevent them from settling out. The application of the surfactants provides the pseudo-plastic properties to cement grout ${ }^{10,11}$. Additionally, anti-washout property is observed when suitable surfactant systems are applied to cement grout. The thixotropic cement mortar shows the good flow performance, placement at depositing. The thixotropic cement grout by application of suitable anionic and cationic surfactant mixtures also provide the adequate pumping pressure and the stability level after placement and consolidation during the dormant period and further more the final concrete hardness increase $\mathrm{e}^{10-16}$.

When cement mortar is applied to marine construction at low temperature below $0{ }^{\circ} \mathrm{C}$, the flow performance, workability, placement, antiwashout and consolidation should be considered in combination. Marine environment indicates the environment surrounded by seawater. Seawater is a complex solution of many salts. The average salt concentration is $3.5 \%$. The salts in seawater decrease the freezing point to below $0{ }^{\circ} \mathrm{C}$. We have studied the application of surfactant admixture system to cement mortar that provides anti-washout property, self

Fresented at The 7th International Conference on Multi-functional Materials and Applications, held on 22-24 November 2013, Anhui University of Science \& Technology, Huainan, Anhui Province, P.R. China 
consolidation for good deformability and high resistance for segregation in cold sea water. This article provides the possible development of surfactant admixtures for concrete grouting agent for low temperature workability.

\section{EXPERIMENTAL}

Cement: The cement used in this study was commercial 'Portland Type I' cement. The chemical compositions and physical properties of the cement are given in Table-1. It is composed of $\mathrm{SiO}_{2}(20 \%), \mathrm{Al}_{2} \mathrm{O}_{3}(5.3 \%), \mathrm{CaO}(62.7 \%), \mathrm{Fe}_{2} \mathrm{O}_{3}$ $(3.7 \%), \mathrm{MgO}(3 \%)$ and small amounts of $\mathrm{Na}_{2} \mathrm{O}, \mathrm{K}_{2} \mathrm{O}$, etc. The density of it is $3.22 \mathrm{~g} / \mathrm{cm}^{3}$ and the surface area is 2,800 $\mathrm{g} / \mathrm{cm}^{2}$.

Preparation of cement grout: Cement mortar refers to the Portland cement slurry without sand or gravel in this study. Cement mortar was prepared by the mixing of mixed surfactants solution and Portland cement ${ }^{7}$. Cationic surfactant used in this experiment was tetraalkyl ammonium chloride (QAC, $25 \%$, FW 320, Aldrich). Dialkyl benzene sulfonate-Na (DBS, $40 \%$, FW 208.21, Aldrich) was used as an anionic surfactant. Poly(methyl vinyl ether) solution (50\%, Aldrich) was applied as polymeric additives. Mixed surfactants by varying the mole ratios of anionic surfactant to cationic surfactant were prepared at $45^{\circ} \mathrm{C}$. Cement mortar was prepared by adding the mixed surfactant solution (1-2 wt \%) to water and cement $(\mathrm{W} / \mathrm{C}=$ $0.5)$ and mixing vigorously at room temperature by hand mixer.

Artificial seawater: For this study, artificial seawater was prepared by adding various salts to waster as shown in Table- $2^{17}$.

Testing of cement mortar properties: The viscosity changes of mortars were conducted by using a commercially available Brookfield rotational viscometer by changing the temperature from room temperature to below $0{ }^{\circ} \mathrm{C}$.

By adding an antiwashout admixture to concrete, its viscosity is increased and its resistance to segregation is enhanced. Acryl chamber $(15 \mathrm{~cm} \times 4.5 \mathrm{~cm} \times 20 \mathrm{~cm})$ was used for the test of antiwashout properties of the mortars.

Measurement of compressive strength of the concrete: The compressive strength of the concrete is the capacity of structure to withstand loads tending to reduce size. The test is done for knowing the compressive strength of hardened concrete. For this purpose, concrete specimens are prepared by cylinder mold $(100 \mathrm{~mm} \times 200 \mathrm{~mm})$ concrete in laboratory. Concrete compressive strength requirements can vary from $17 \mathrm{MPa}$ for residential concrete to $28 \mathrm{MPa}$ and higher in commercial structure. Cylinders tested for acceptance and quality control are made and cured in accordance with procedures described for standard cured specimens in ASTM C 31 Standard Practice for Making and Curing Test Specimens in The Field. Cylindrical specimens are tested in accordance with ASTM C 39, Standard Test Method for Compressive Strength of Cylindrical Concrete Specimens. After casting, all specimens were left in molds and cured in the air or in the seawater. The tests were performed at age of 7, 15 and 28 days. For each age, the compressive strength was averaged from three specimens tested.

\section{RESULTS AND DISCUSSION}

Cement mortar mixed both cationic and anionic surfactants exhibits shear-thinning behaviour whereby apparent viscosity decreases with the increase of shear rate. The mortar containing such a property is called thixotropic concrete where the viscosity buildup is promoted due to the association and entanglement of different charge properties at a low shear rate that can decrease the flow and increase the viscosity. Fig. 1 shows the viscosity of the mortar as the molar ratio of tetraalkyl ammonium chloride to dialkyl benzene sulfonate-Na changes. As the tetraalkyl ammonium chloride ratio increases the viscosity increases, whereas as the dialkyl benzene sulfonate-Na ratio increases the viscosity decreases. When the molar ratio of tetraalkyl ammonium chloride to dialkyl benzene sulfonateNa was 1.2-1.0 or 1-1, the antiwashout properties of the mortar were observed at minimum amount amounts applied (Fig. 1).

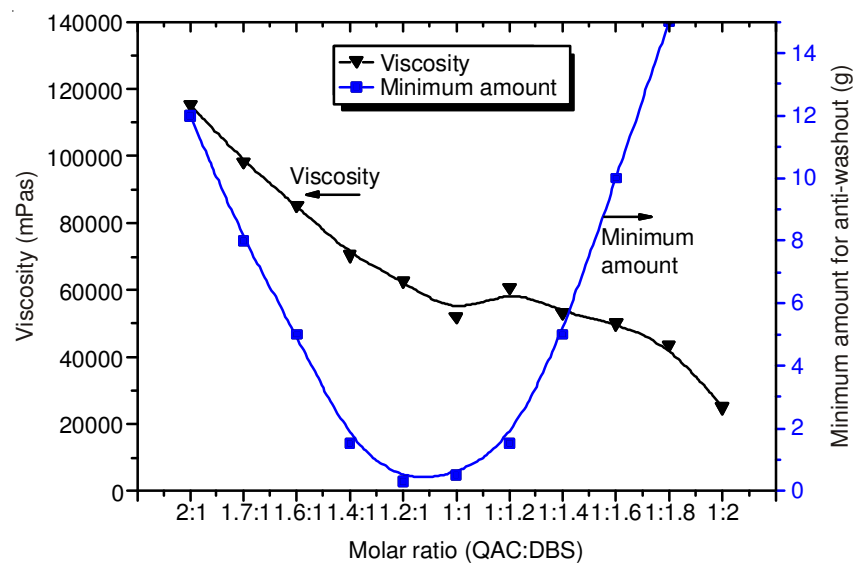

Fig. 1. Viscoelastic changes as the molar ratio of QAC/DBS changes

Table- 3 shows the freezing temperature of mortar decrease by solvent addition. When 2-propanol is added by $20 \%$ to mixed surfactant system (the composition of QAC/DBS/

\begin{tabular}{ccccccccc}
\multicolumn{10}{c}{ TABLE-1 } \\
\hline \multicolumn{8}{c}{ CHEMICAL COMPOSITIONS AND PHYSICAL PROPERTIES OF CEMENT } \\
\hline $\mathrm{SiO}_{2}$ & $\mathrm{Al}_{2} \mathrm{O}_{3}$ & $\mathrm{Fe}_{2} \mathrm{O}_{3}$ & $\mathrm{CaO}$ & $\mathrm{MgO}$ & $\mathrm{Na}_{2} \mathrm{O}$ & Free limes & Density $\left(\mathrm{g} / \mathrm{cm}^{3}\right)$ & Surface area $\left(\mathrm{cm}^{2} / \mathrm{g}\right)$ \\
\hline 20 & 5.3 & 3.7 & 62.7 & 3 & 2.1 & 3.2 & 3.22 & 2,800 \\
\hline
\end{tabular}

TABLE-2

CHEMICAL COMPOSITION OF ARTIFICIAL SEAWATER

\begin{tabular}{lccccc}
\hline \multicolumn{1}{c}{ Compound } & $\mathrm{NaCl}$ & $\mathrm{MgCl}_{2}$ & $\mathrm{Na}_{2} \mathrm{SO}_{4}$ & $\mathrm{CaCl}_{2}$ & $\mathrm{KCl}$ \\
\hline Concentration $(\mathrm{g} / \mathrm{L})$ & 24.53 & 5.2 & 4.09 & 1.16 & 0.695 \\
\hline Compound & $\mathrm{NaHCO}_{3}$ & $\mathrm{KBr}$ & $\mathrm{H}_{3} \mathrm{BO}_{3}$ & $\mathrm{SrCl}_{2}$ & $\mathrm{NaF}$ \\
\hline Concentration $(\mathrm{g} / \mathrm{L})$ & 0.201 & 0.101 & 0.027 & 0.025 & 0.003 \\
\hline
\end{tabular}




\begin{tabular}{|c|c|c|c|c|c|c|c|}
\hline \multirow{3}{*}{ Sample No. } & \multicolumn{6}{|c|}{$\begin{array}{c}\text { TABLE-3 } \\
\text { FREEZING TEMPERATURE DECREASE BY SOLVENT ADDITION }\end{array}$} & \\
\hline & \multirow{2}{*}{ Solvent } & \multirow{2}{*}{$\begin{array}{l}\mathrm{Wt} \% \text { in mixed } \\
\text { micelle }(\%)\end{array}$} & \multirow{2}{*}{$\begin{array}{l}\text { Ratio (QAC: } \\
\text { DBS) }\end{array}$} & \multicolumn{4}{|c|}{ Freezing test } \\
\hline & & & & $0{ }^{\circ} \mathrm{C}$ & $-3^{\circ} \mathrm{C}$ & $-6^{\circ} \mathrm{C}$ & $-9^{\circ} \mathrm{C}$ \\
\hline 1 & Methanol & 10 & $1.2: 1$ & $\mathrm{~F}$ & $\mathrm{~F}$ & I & $I$ \\
\hline 2 & Methanol & 10 & $1: 1$ & I & I & I & I \\
\hline 3 & Methanol & 20 & $1.2: 1$ & F & F & $\mathrm{F}$ & F \\
\hline 4 & Methanol & 20 & $1: 1$ & I & I & I & I \\
\hline 5 & Ethanol & 10 & $1.2: 1$ & $\mathrm{~F}$ & I & I & I \\
\hline 6 & Ethanol & 10 & $1: 1$ & I & I & I & I \\
\hline 7 & Ethanol & 20 & $1.2: 1$ & $\mathrm{~F}$ & F & F & I \\
\hline 8 & Ethanol & 20 & $1: 1$ & I & I & I & I \\
\hline 9 & 1-Propanol & 10 & $1.2: 1$ & I & I & I & I \\
\hline 10 & 1-Propanol & 10 & $1: 1$ & I & I & I & I \\
\hline 11 & 1-Propanol & 20 & $1.2: 1$ & F & I & I & I \\
\hline 12 & 1-Propanol & 20 & $1: 1$ & I & I & I & I \\
\hline 13 & 2-Propanol & 10 & $1.2: 1$ & I & I & I & I \\
\hline 14 & 2-Propanol & 10 & $1: 1$ & I & I & I & I \\
\hline 15 & 2-Propanol & 20 & $1.2: 1$ & F & F & F & F \\
\hline 16 & 2-Propanol & 20 & $1: 1$ & I & I & I & I \\
\hline 17 & $n$-Butanol & 10 & $1.2: 1$ & I & I & I & I \\
\hline 18 & n-Butanol & 10 & $1: 1$ & I & I & I & I \\
\hline 19 & $n$-Butanol & 20 & $1.2: 1$ & F & $\mathrm{F}$ & F & $\mathrm{F}$ \\
\hline 20 & $n$-Butanol & 20 & $1: 1$ & I & I & I & I \\
\hline 21 & $n$-Heptanol & 10 & $1.2: 1$ & F & F & I & I \\
\hline 22 & $n$-Heptanol & 10 & $1: 1$ & $\mathrm{~F}$ & I & I & I \\
\hline 23 & $n$-Heptanol & 20 & $1.2: 1$ & I & I & I & I \\
\hline 24 & $n$-Heptanol & 20 & $1: 1$ & $\mathrm{~F}$ & $\mathrm{~F}$ & I & I \\
\hline 25 & $n$-Octanol & 10 & $1.2: 1$ & $\mathrm{~F}$ & $\mathrm{~F}$ & I & I \\
\hline 26 & n-Octanol & 10 & $1: 1$ & F & I & I & I \\
\hline 27 & $n$-Octanol & 20 & $1.2: 1$ & F & F & I & I \\
\hline 28 & n-Octanol & 20 & $1: 1$ & F & I & I & I \\
\hline 29 & $n$-Hexane & 10 & $1.2: 1$ & I & I & I & I \\
\hline 30 & $n$-Hexane & 10 & $1: 1$ & I & I & I & I \\
\hline 31 & $n$-Hexane & 20 & $1.2: 1$ & $\mathrm{~F}$ & F & I & I \\
\hline 32 & $n$-Hexane & 20 & $1: 1$ & I & I & I & I \\
\hline
\end{tabular}

PMVE/IPA $=1.2 / 1 / 0 / 0.05 / 0.44)$, the freezing temperature was decreased to below $-9^{\circ} \mathrm{C}$. Fig. 2 shows that the addition of mixed surfactant admixture to cement mortar increases its thixotropic, suitable antiwashout, proper workability and self-leveling properties. When mixed surfactant admixture is applied to cement mortar, the slurry was leveled without washout to water (Fig. 2a).
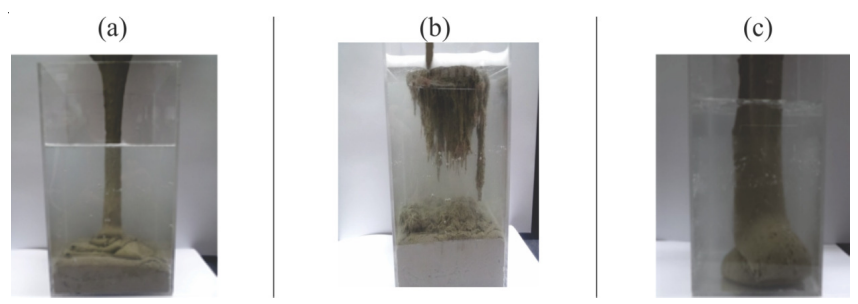

Fig. 2. Antiwashout properties at $-3{ }^{\circ} \mathrm{C}$ in the seawater grouting. (a) $\mathrm{W} / \mathrm{C}=$ 0.5 , sample 15 , (b) $\mathrm{W} / \mathrm{C}=0.5$, no mixed surfactant admixture and (c) $\mathrm{W} / \mathrm{C}=0.5$, after addition of commercial anti washout admixture by 2 wt $\%$

Fig. 3 shows the viscosity changes of the mortar at different temperature. The viscosity properties at low temperature can be controlled by IPA content applied to cement mortar. Fig. 4 shows the compressive strength as the curing time changes. As the concentration of mixed surfactant admixture

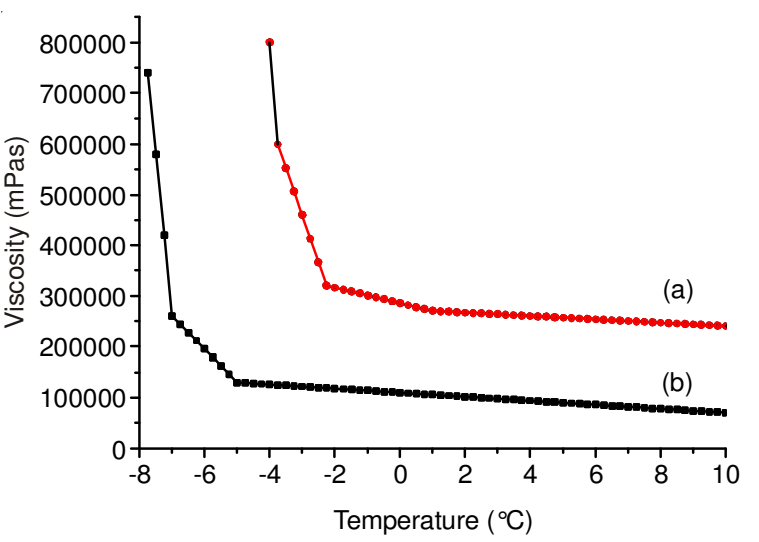

Fig. 3. Viscosity changes as the temperature of concrete mortar decrease. (a) $\mathrm{QAC} / \mathrm{DBS} / \mathrm{PVME}=1.2 / 1 / 0 / 05,1 \mathrm{wt} \%$ applied to $\mathrm{W} / \mathrm{C}=0.5$ mortar (b) QAC/DBS/PVME/IPA = 1.2/1/0/05/0.44, $1 \mathrm{wt} \%$ applied to $\mathrm{W} / \mathrm{C}=0.5$ mortar

increases, the compressive strength increases. We suggest that the concrete is packed densely and cured strongly as the mixed surfactant admixture introduction increases. The compressive strength was above $20 \mathrm{MPa}$ when $1 \%$ of the mixed surfactant admixture is applied to cement mortar and cured in the air. The strength slightly increases as curing time increases. As the mortar is cured in the seawater, it takes a month to reach the compressive strength more than $20 \mathrm{MPa}$ (Fig. 5). 


\begin{tabular}{cccccc}
\hline \multicolumn{7}{c}{ TABLE-4 } \\
\hline \multicolumn{7}{c}{ COMPRESSIVE STRENGTH RATIO AT CURING CONDITION (SEAWATER/AIR) } \\
\hline 7day & \multicolumn{4}{c}{ 15day } & \multicolumn{2}{c}{ 28day } \\
\hline Wt \% in mortar (\%) & Seawater/air (\%) & Wt \% in mortar (\%) & Seawater/air (\%) & Wt \% in mortar (\%) & Seawater/air (\%) \\
\hline 0.50 & 83 & 0.50 & 80 & 0.50 & 86 \\
0.75 & 80 & 0.75 & 85 & 0.75 & 90 \\
1.00 & 87 & 1.00 & 90 & 1.00 & 86 \\
\hline
\end{tabular}

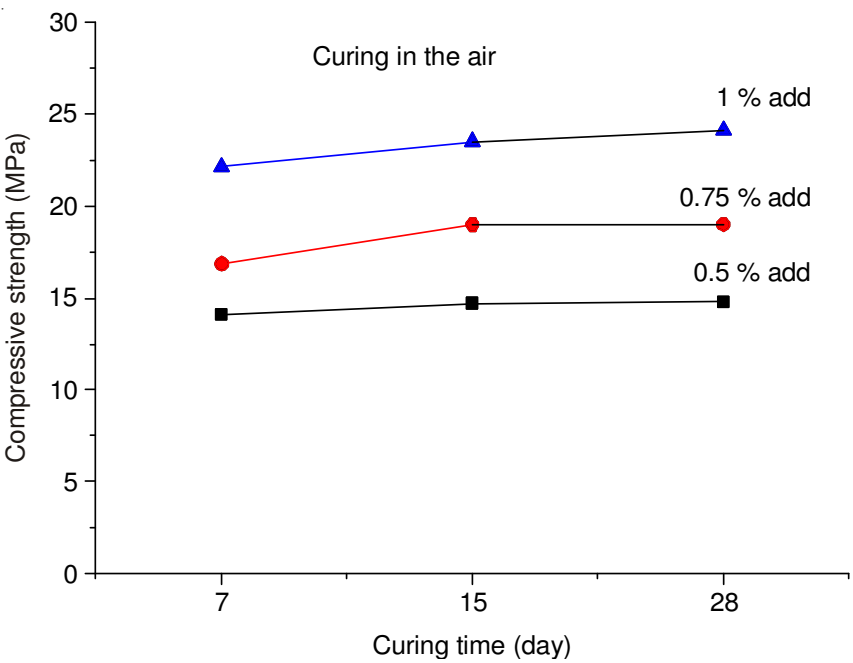

Fig. 4. Compressive strength of cement mortar after curing in the air

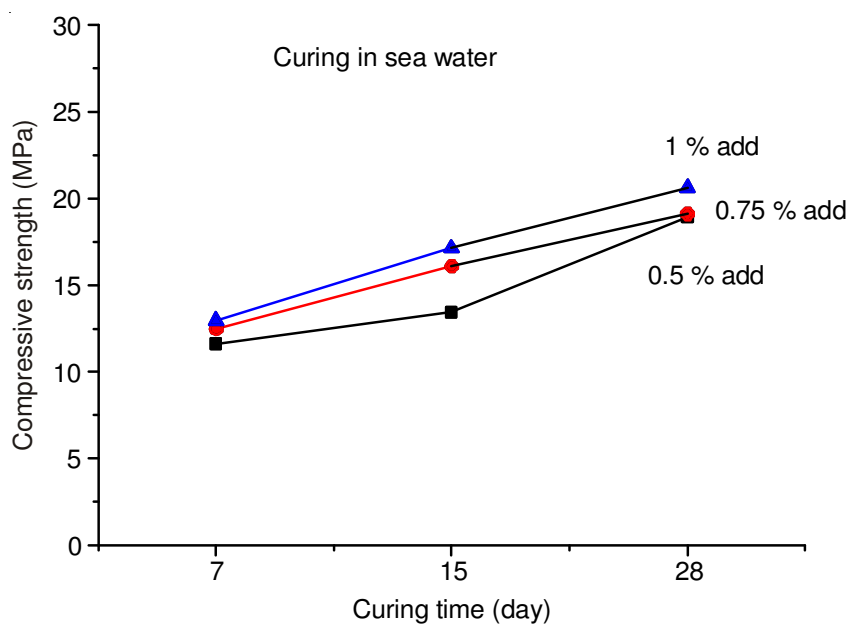

Fig. 5. Compressive strength of cement mortar after curing in the seawater

Table-4 shows the compressive strength ratio at curing in the seawater and in the air. As the mixed surfactant admixture added to concrete mortar by $0.5-1.0 \mathrm{wt} \%, 20 \%$ decrease of compressive strength curing in the seawater was observed.

\section{Conclusion}

Cement mortar mixed both cationic and anionic surfactants exhibits thixotropic properties. When the molar ratio of tetraalkyl ammonium chloride to dialkyl benzene sulfonateNa was $1.2: 1$ or $1: 1$, the antiwashout properties of the mortar were observed at minimum amount amounts applied. The freezing temperature can be reduced by adding solvent such as 2-propanol to below $-5^{\circ} \mathrm{C}$. The viscosity properties of the mortar at low temperature can be controlled by IPA content applied to cement mortar. The compressive strength was above $20 \mathrm{MPa}$ when $1 \%$ of the mixed surfactant admixture is applied to cement mortar and cured in the air. However, the strength was reduced by $20 \%$ after curing in the seawater.

\section{ACKNOWLEDGEMENTS}

This study was supported by Korean Research Council for Industrial Science and Technology (2012-0106).

\section{REFERENCES}

1. J. Falbe, Surfactants in Consumer Products; Springer-Verlag Berlin Heidelberg: New York, Ch. 4 (1987).

2. G. Kume, M. Gallotti and G. Nunes, J. Surfact Deterg., 11, 1 (2008).

3. K.L. Stellner and J.F. Scamehorn, J. Am. Oil Chem. Soc., 63, 566 (1986).

4. M.J. Rosen, Surfactant and Interfacial Phenomena, Wiley, New York edn 2, Ch. 1-3 (1989).

5. M.J. Rosen and X.Y. Hua, J. Am. Oil Chem. Soc., 59, 582 (1982).

6. A. Upadhyaya, E.J. Acosta, J.F. Scamehorn and D.A. Sabatini, J. Surfact. Deterg., 9, 169 (2006).

7. I.K. Jang, S.R. Seo and S.K. Park, Appl. Chem. Eng., 23, 480 (2012).

8. Y. Hotaka, K. Koji and S. Daisuke, US Patent 8,105,500 B2 (2012).

9. Y.H. Kim, Appl. Chem. Eng., 21, 457 (2010).

10. W.C. Jau and C.T. Yang, Cement Concr. Compos., 32, 450 (2010).

11. K.H. Khayat and J. Assaad, ACI Mater. J., 100, 185 (2003).

12. V.H. Nguyen, S. Remond and J.L. Gallias, Cement Concr. Res., 41, 292 (2011).

13. S.H. Bae, J.I. Park and T.D. Kim, J. Korean Soc. Urban Environ, 10, 259 (2010).

14. H. El-Chabib, M. Nehdi and M. Sonebi, ACI Mater. J., 100, 165 (2003).

15. J.J. Assaad and C.A. Issa, Constr. Build. Mater., 30, 667 (2012).

16. C.F. Ferraris, J. Res. Natl. Inst. Stand. Technol., 104, 461 (1999).

17. M.M. Islam, M.S. Islam, B.C. Mondal and M.R. Islam, J. Civ. Eng., 28, 129 (2010) 